\title{
PESQUISAS SOBRE A EDUCAÇÃO DOS SENTIDOS E DAS SENSIBILIDADES NA HISTÓRIA DA EDUCAÇÃO: ALGUMAS INDICAÇÕES TEÓRICO- METODOLÓGICAS
}

\author{
Marcus Taborda de Oliveira ${ }^{1}$
}

\section{RESUMO}

O trabalho foca em alguns pressupostos teórico-metodológicos para pensar as pesquisas sobre a história da educação dos sentidos e das sensibilidades. Mobiliza autores que refletem sobre a experiência e a materialidade da vida, sugerindo que os corpos ocupam um entre-lugar nas relações entre natureza e cultura. Defende que que a sua educação é sempre dialógica, contrapondo-se ao hipersubjetivismo contemporâneo. Finaliza oferecendo exemplos de trabalhos neste âmbito de estudos.

Palavras-chave: história social da educação, história da educação dos sentidos e das sensibilidades, historiografia.

\section{INVESTIGACIÓN SOBRE LA EDUCACIÓN DE LOS SENTIDOS Y DE LA SENSIBILIDAD EN LA HISTORIA}

\footnotetext{
${ }^{1}$ Universidade Federal de Minas Gerais (UFMG), Belo Horizonte/MG, Brasil.
} 


\title{
DE LA EDUCACIÓN: ALGUNAS INDICACIONES TEÓRICAS Y METODOLÓGICAS
}

\section{RESUMEN}

El trabajo se centra en algunos supuestos teóricos y metodológicos para pensar sobre la historia de la educación de los sentidos y las sensibilidades. Moviliza a los autores que reflexionan sobre la experiencia y la materialidad de la vida, sugiriendo que los cuerpos ocupan un entre-lugar en la relación entre la naturaleza y la cultura. Argumenta que su educación es siempre dialógica, en contraste con el hiperesubjetivismo contemporáneo. Concluye ofreciendo ejemplos de trabajos en este campo de estudios.

Palabras-clave: historia social de la educación, historia de la educación de los sentidos y sensibilidades, historiografia.

\section{RESEARCH ON SENSE AND SENSIBILITIES EDUCATION IN HISTORY OF EDUCATION: SOME THEORETICAL METHODOLOGICAL INDICATIONS}

\begin{abstract} field of studies. historiography.

\section{RECHERCHE SUR L'ÉDUCATION AU SENS ET À LA SENSIBILITÉ DANS L'HISTOIRE DE L'ÉDUCATION: QUELQUES INDICATIONS THÉORIQUES ET MÉTHODOLOGIQUES}

The work focuses on some theoretical and methodological assumptions to think about the history of the education of the senses and sensibilities. It uses authors who reflect on the experience and materiality of life, suggesting that bodies occupy a in-between place in the relationship between nature and culture. It argues that their education is always dialogical, in contrast to contemporary hyper subjectivism. It concludes offering examples of works in this

Keywords: social history of education, history of education of the senses and sensibilities,

\section{RESUMÉ}

Le travail se centre sur des présupposés théorico-méthodologiques permettant de réfléchir sur l'histoire de l'éducation des sens et des sensibilités. Il mobilise des auteurs qui réfléchissent sur l'expérience et la matérialité de la vie, en suggérant que les corps occupent une entredeux dans la relation entre nature et culture. Il soutient que leur éducation est toujours dialogique, contrairement à l'hypersubjectivisme contemporain. Il conclut en proposant des exemples de travaux dans ce domaine d'études.

Mots-clés: histoire sociale de l'éducation, histoire de l'éducation des sens et des sensibilités, historiographie. 


\section{INTRODUÇÃO}

Quando contemplo um homem situado fora de mim e à minha frente, nossos horizontes concretos, tais como são efetivamente vividos por nós dois, não coincidem. Por mais perto de mim que possa estar esse outro, sempre verei e saberei que ele próprio, na posição que ocupa, e que o situa fora de mim e à minha frente, não pode ver: as partes do seu corpo inacessíveis ao seu próprio olhar - a cabeça, o rosto, a expressão do rosto -, o mundo ao qual ele dá as costas, toda uma série de objetos e de relações que, em função da respectiva relação em que podemos situar-nos, são acessíveis a mim e inacessíveis a ele. Quando estamos nos olhando, dois mundos diferentes se refletem na pupila dos nossos olhos. (BAKHTIN, 1997, p. 43)

El modo de la percepción sensorial cambia, junto con el modo total de existencia de los colectivos históricos, dentro de grandes espacios históricos de tiempo. El modo, bajo el qual se organiza la percepción humana (el médio en el que ésta se desarrolla), está condicionado no solo natural sino también historicamente. (BENJAMIN, 2009, p. 93)

\section{COMO E O QUE INVESTIGAR QUANDO SE TRATA DA HISTÓRIA DA EDUCAÇÃO DOS SENTIDOS E DAS SENSIBILIDADES?}

Ao problematizar a potência do estudo dos sentidos e das sensibilidades no âmbito das pesquisas em História da Educação, procurei mostrar como essa temática, recentemente tornada uma rubrica, quiçá uma moda, já estava presente nas mais diversas tradições historiográficas (Taborda de Oliveira, 2018). Percorrendo um grande espectro que vai dos trabalhos sobre a Paidéia grega, passando pelos estudos da gestualidade e da voz de importantes medievalistas, até chegar nas peculiaridades recentes dos interesses pela cultura material e pela história do corpo, muitos autores, de diferentes escolas históricas, tiveram e têm no seu horizonte preocupações com formas diversas de educar os sentidos - olhar, tato, olfato, audição e paladar - frequentemente motivados pelo interesse de compreender padrões de transformações no que podemos chamar sensibilidades. Estas se "estabilizariam" nos sentimentos, nas 
emoções, nos afetos, nos comportamentos, na linguagem que cada indivíduo ou grupo social imerso em uma sociedade específica, produziria, permitindo que pensemos em uma dimensão estética da existência (Taborda de Oliveira, 2018a, p. 3).

Essa vastíssima possibilidade de estudos históricos sobre os sentidos e as sensibilidades nos lança ao desafio de compreender as respostas individuais e coletivas - que todos dão aos impulsos que recebem do meio (ambiente, natureza, cultura, sociedade, realidade...), de modo que novas formas de pensar, agir e sentir sejam mobilizadas em relação às antigas, que podem perdurar, ser ressignificadas ou "esquecidas". Portanto, parto do entendimento que não é possível estudar as sensibilidades sem que, ato contínuo, estudemos os sentidos, essas janelas que fazem a mediação entre o mundo interior e o exterior em cada um de nós. Daí que, no grupo que vem trabalhando junto nos últimos 7 anos, o par sentidos/sensibilidades tenha se convertido em um dos descritores mais privilegiados, seja empírica ou teoricamente. $^{2}$

Essa premissa nos leva a reconhecer imediatamente que esse veio de investigações está radicalmente atrelado à materialidade da vida, à corporalidade na sua expressão mais plena. Sem negligenciar, contudo, a linguagem, importante inclusive na sua dimensão prescritiva, pois também ela é uma atividade inscrita na concretude da vida em sociedade, ancorada em relações polimórficas e polifônicas, nas quais as dimensões simbólicas estão inextricavelmente ligadas à vida material ordinária de um dado grupamento social, como bem mostrou Mikhail Bakhtin (1999 e 2011) ao tratar da sua dimensão histórico-material. Na acepção do autor russo, o princípio dialógico é estruturante da vida social, na medida em que nos constituímos no mesmo movimento que somos constituídos pela "voz" do(s) outro(s). Na sua reflexão,

\footnotetext{
2 Trata-se do Núcleo de Pesquisas sobre a Educação dos Sentidos e da Sensibilidades - NUPES, alocado na Faculdade de Educação da UFMG, mas com ramificações em outras universidades brasileiras e no exterior. Os outros descritores ali mobilizados são: trabalho/labor, formação, educação social, tempo livre e modernidade. http://dgp.cnpq.br/dgp/espelhogrupo/1182439018750865
} 
segundo o meu entendimento, o outro pode ser também a natura, com quem estabelecemos os mais variados tipos de relação. Isso porque, seguindo a tópica bakhtiniana, que seria recuperada por Raymond Williams, existiriam ao menos três tipos de relação que constituiriam a totalidade da vida: 1) as relações entre os objetos do mundo (as coisas, os fenômenos físicos, químicos etc.); 2) as relações entre o sujeito e aqueles objetos; 3) as relações entre sujeitos (de afeto, de respeito, de poder, éticas etc.).

Portanto, pesquisar sobre a educação dos sentidos e das sensibilidades nos impele a inventariar como o corpo se configurou historicamente no entrelugar da cultura, tomada na sua dimensão simbólica, com a natureza, expressão do mundo físico, fenomênico, transformando constantemente a primeira e ressignificando a segunda, segundo a perspectiva dialógica. Assim, de acordo com a sugestão de Esposito (2016), o corpo não seria apenas um meio da nossa humanização, mas também atualizaria em nós resquícios do mundo físico, material. Este autor questiona os fundamentos históricos da dicotomia pessoas/coisas, classicamente reafirmada pela separação entre corpo e espírito, sendo o segundo a razão de ser da existência do primeiro. Um olhar atento para a educação dos sentidos e das sensibilidades ao longo da história tem ajudado a questionar aquele tipo de representação dicotômica, justamente por mostrar que o pensamento não pode subsistir sem o corpo no qual ele se manifesta, e sem os suportes materiais que lhe dão longevidade, embora a tradição formativa ocidental tenha privilegiado o "espírito", o intelecto, as ideias, o pensamento. Ao mesmo tempo, não se trata de ignorar essa dimensão da vida, pois o corpo também se transforma na medida em que sobre ele são produzidas tanto as mais diversas e conflitantes representações, quanto um sem número de ações, em um intercâmbio permanente entre as dimensões físico-materiais e simbólico-culturais. Daí a sugestão de que o corpo é este entre-lugar que (re)integra dialogicamente pessoas e coisas, ideias e ações, representações e comportamentos, vetor por excelência de experiências que produzem e reproduzem a vida. Devemos admitir, por isso, que os sentidos devem ser compreendidos na sua dupla dimensão: aquela biológica ou natural, 
eminentemente corpórea e manifesta na capacidade para ouvir, ver, tatear, degustar e cheirar, mas também no que representa do ponto de vista simbólico, semiótico, a capacidade dos sujeitos para significar, representar, imaginar, com toda a sua ancoragem cultural. Esse diálogo, matéria prima do historiador que se ocupa da educação dos sentidos e das sensibilidades, é obra sempre aberta:

A única forma adequada de expressão verbal da autêntica vida do homem é o diálogo inconcluso. A vida é dialógica por natureza. Viver significa participar do diálogo: interrogar, ouvir, responder, concordar, etc. Nesse diálogo o homem participa inteiro e com toda a vida: com os olhos, os lábios, as mãos, a alma, o espírito, todo o corpo, os atos. Aplica-se totalmente na palavra, e essa palavra entra no tecido dialógico da vida humana, no simpósio universal (BAKHTIN, 2011, p. 348 , destaques no original).

Assim, tratam-se de corpos de sujeitos que produzem práticas que são, também elas, constantemente transformadas pela dimensão simbólica que emana de e atravessa toda cultura. Os exemplos são muitos. $\mathrm{O}$ ato de ler, nas suas múltiplas formas, pressupõe os sentidos corporais (o tato e a visão, talvez mais intensamente). Se refinamos ou regredimos a nossa capacidade de decodificar e fruir sons, é porque temos um aparato biológico que o permite. A gastronomia se converte para alguns em uma forma refinada de cultura porque mobiliza o paladar, a visão o tato. Nosso sentimento de nojo, de repulsa, de classificação de odores, surgiu justamente porque temos órgãos capazes de discriminar as emanações do meio ambiente. Até mesmo as nossas manifestações políticas, não raro estão implicadas nas sensações que capturamos com os nossos corpos, e a gestualidade de oponentes políticos parece confirmar esse pressuposto (ANSART, 2019; BRESCIANI E NAXARA, 2004; BREPOHL et alii, 2012).

Em todos esses exemplos, os sentidos assumem aquele duplo caráter antes aludido. Se eles são, por um lado, as janelas que permitem a nossa comunicação com o mundo, por outro, na medida em que somos sempre e necessariamente seres sociais, ajudam a produzir os “sentidos" de nojo, do belo, 
do grotesco, do normal ou anormal, que são marcadores simbólicos das diferentes sociedades, logo, são culturalmente produzidos. Assim, o estudo histórico dos sentidos e das sensibilidades é um desdobramento bem-vindo dos estudos sobre o corpo em toda sua expressividade e potência, na tentativa de compreender o que fizeram as pessoas e os grupos sociais com os impulsos que receberam do meio, de modo a transformá-los em sensibilidades novas, ressignificadas ou perenes, pela via da linguagem, da cultura, da interação dialógica, a qual reconciliaria natureza e cultura. Caracterizando a visão carnavalesca do mundo, esmiuçada na sua obra sobre François Rabellais, Bakhtin comenta que

O indivíduo parecia dotado de uma segunda vida que lhe permitia estabelecer relações novas, verdadeiramente humanas, com os seus semelhantes. $O$ autêntico humanismo que caracterizava essas relações não era em absoluto fruto da imaginação ou do pensamento abstrato, mas experimentava-se concretamente nesse contato vivo, material e sensível. O ideal utópico e o real baseavam-se provisoriamente na percepção carnavalesca do mundo, única no gênero (BAKHTIN, 1999, p. 9).

É de experiência que se trata, e de uma cultura comum que permitia uma visão integrada do mundo "material e sensível".

\section{SENTIDOS E SENSIBILIDADES}

Referência importante para pensar a história da educação dos sentidos, Peter Gay definiu a experiência como "o encontro da mente com o mundo", muito próximo do que propuseram Walter Benjamin e Edward Thompson, a despeito das diferentes filiações teórico-historiográficas dos três autores. Para ele os sentidos, parte do nosso aparato biológico, são educados de modo a permitir o desenvolvimento de sensibilidades. Logo, assim como Coccia (2016) e Esposito (2016), o autor se encontra entre aqueles que não negligencia as 
dimensões materiais da vida. Nomearmos os cinco sentidos como historicamente os nomeamos não oblitera o fato de que é a partir do nosso complexo aparato perceptivo que interagimos com o mundo, seja físico (natural) ou social, duas faces complementares de uma mesma "realidade" tangível. A exploração do mundo se dá pela via do corpo - dos sentidos corporais - e é esse o caminho que levaria à consolidação dos processos de formação. Em outros termos, produziria ou transformaria sensibilidades (TABORDA DE OLIVEIRA, 2012).

Estas, por sua vez, são respostas dadas àqueles estímulos, e ganham maior ou menos estabilidade conforme as suas emanações afetaram de forma mais ou menos significativa o fluxo da vida. Assim, nem tudo que experimentamos pelos nossos sentidos se converteria em comportamento duradouro. O efeito de um choque elétrico, por exemplo, pode ser apenas o de uma sensação de desconforto momentâneo em função da nossa sensibilidade neural. Mas pode nos ensinar a ter medo, respeito, aversão, pânico, paixão pela eletricidade. Assim como o ato de aprender a desenhar as letras pode ser algo que provoque satisfação em alguns e tédio ou angústia em outros. Ou ainda, o ato de aprender a tocar um instrumento ou cozinhar pode significar um encontro exultante com os influxos do mundo, mas também uma experiência traumática. Ou seja, essa sensibilidade pode ser fugaz e fugidia. Mas pode, também, se converter em sentimentos, comportamentos, atitudes que assumem um caráter duradouro. Podem ser espontâneos, fruto das trocas sociais não previstas, manifestas em todas as formas de educação social, ou deliberadas, quando são desejadas, prescritas e estimuladas. O uso dos sentidos leva, necessariamente, a formas de decodificação dos sinais emitidos pelo mundo externo, pois as sensibilidades são resultado da nossa capacidade responsiva e dialógica, produtos e produtoras de experiência.

Essas respostas não são ou devem ser, necessariamente, "positivadas" de forma anacrônica. Se os castigos corporais, por exemplo, já foram normalizados e regulamentados para uso nas escolas, e mesmo eventualmente 
reivindicados por pais e professores, hoje parece haver outro tipo de sensibilidade em relação aos limites, à ineficiência, ou simplesmente a violência da punição corporal. Se surgiram inúmeras prescrições no âmbito da psicologia do trabalho nas décadas iniciais do século $\mathrm{XX}$, provavelmente isso tem a ver com diversos diagnósticos em relação aos problemas da fadiga física ou mental, e os efeitos do trabalho árduo sobre a vida dos trabalhadores. Isso levaria, por sua vez, a um conjunto de prescrições sobre o tempo livre e as práticas de lazer, as quais se assentaram ao longo do tempo (CORBIN, 2001). Logo, o que era “comum" em uma época não permanece "comum" ou "normal” em outros tempos e lugares, pois a experiência, as estruturas de sentimentos e ações sobre o corpo em cada sociedade mudam, variam, ganham outra dimensão, alterando costumes, produzindo novos comportamentos e sentimentos, não raro a partir ou pelo efeito de práticas educativas.

Portanto, o que permanece como vestígio dos sentidos e das sensibilidades, para nós, muito provavelmente tem a ver com aquilo que ganhou permanência, uma relativa estabilidade no âmbito da cultura e da sociedade, o que nos ajuda a acautelarmo-nos contra todas as formas de "subjetivismo". 3

3 Problematizando o desenvolvimento histórico da palavra sensibilidade, e assumindo a dificuldade em relação à polissemia da mesma, Raymond Williams mostrou como o seu aparecimento em língua inglesa (sensibility) remonta ao século XIV, denotando aquilo que pode ser "sentido, percebido por meio dos sentidos" (2007, p. 366). No seu processo de afirmação significou, no século XVIII, a possibilidade de "uma generalização social de certas qualidades pessoais ou, em outras palavras, uma apropriação pessoal de certas qualidades sociais" (p. 367). Significou, ainda, uma oposição à "racionalidade" ou "intelectualidade", no século XIX, até se tornar corrente na linguagem estética para designar gosto, cultivo, discriminação ou crítica, perdendo força ao longo dos anos 1960, segundo o autor. Na sua formulação original tinha relação com sensible, de origem francesa.

Já, na tradição francesa, segundo oDictionnaire de l'historien (Gauvard e Sirinelli, 2015), teria havido um sensual turn, contra o que seria "uma disciplina histórica excessivamente intelectualista" (p. 643). No verbete sensibilitè, do referido dicionário, podemos ler: "O postulado dessa história é a historicidade da hierarquia de sentidos, das maneiras de perceber, de sentir [sentir], de experimentar a sensação física [ressentir]. Não se trata apenas de traçar o universo sensorial de outro tempo, é necessário também reconstituir as modalidades da atenção e da apreciação, colocando a questão dos limites de tolerância às mensagens sensoriais, conceito central aqui [...], que inaugura a pesquisa sobre as figuras do desejo e da repulsão, sobre o imaginário social. Outro conceito essencial, o de 'cultura sensível', em virtude do qual uma sociedade dada tem sua própria maneira de sentir, de experimentar, de olhar, de escutar etc. em função de suas crenças, saberes, representações, normas e valores" (2015, pp. 643-644). 


\section{MATERIALIDADE DA VIDA ORDINÁRIA E CULTURA COMUM: CAMINHOS PARA INVESTIGAR SENTIDOS E SENSIBILIDADES NA HISTÓRIA DA EDUCAÇÃO DOS TRABALHADORES.}

Se muitos autores se prestam à compreensão histórica da educação dos sentidos e das sensibilidades, justamente pela ênfase dada à dimensão material da vida, dois, em especial, cunharam noções importantes para os propósitos dos meus investimentos de pesquisa, em franca relação com a perspectiva dialógica de Mikhail Bakhtin e com a história social proposta por Walter Benjamin, ancorada na memória, nos sentidos, na experiência (Bakhtin, 2011; Benjamin, 2013). No caso de Edward Thompson as noções de experiência e economia moral têm permitido distanciamento tanto da perspectiva economicista do marxismo clássico, da despersonalização própria da voga estruturalista, mas também do hiper-subjetivismo que assolou a pesquisa nas Humanidades nas décadas finais do século XX e no início do século XXI. Já, estrutura de sentimentos e cultura comum são duas noções recorrentes no léxico de Raymond Williams, as quais ajudam a compreender os lentos e plurais processos de transformação cultural e social que teriam concorrido para a afirmação de determinados padrões de comportamento e sentimento em detrimento de outros, às vezes mais longevos, mas menos vigorosos conforme as sociedades se transformam, sempre em uma chave no qual o mutualismo e a reciprocidade ganharam mais ou menos densidade. Ambos os autores, em algumas das suas obras de maior envergadura, sem aderir à rubrica sentidos/sensibilidades, embora constantemente evoquem a sua transformação,

O Dicionariode la Lengua Española define sensibilidad como: 1. Faculdade de sentir, própria dos seres animados; 2. Qualidade de sensível; 3. Maneira peculiar de sentir ou de pensar (Dicionario de la Lengua Española, 2017). Disponível em: http://dle.rae.es/?id=XaAackN. Acesso em 29 de março de 2018.

Por fim, o sitio Garzanti Linguistica, de língua italiana, define sensibilità como: "1. a faculdade de organismos animais de perceber estímulos externos ou internos através de estruturas sensoriais e sensoriais; 2. aptidão para sentir fortemente emoções, afetos, sentimentos". Disponível em: https://www.garzantilinguistica.it/. Acesso em 20 de maio de 2018.

Nos quatro casos acima, sensibilidade advém do latim sensibilitas, denotando sentido, significado, sensibilidade. 
trataram justamente das formas mobilizadas por diferentes sujeitos individuais ou coletivos para transformar necessidades e expectativas conforme a contingência histórica os impelia à ação, ora conservadora, ora rebelde e/ou contestatória (THOMPSON, 1976, 1978, 1987, 1998, 2003; WILLIAMS, 1961, 1968; 1976, 1991, 2003).

A experiência, para ambos, nunca pode ser definida exclusivamente em termos individuais. Antes, se ela representa "uma exploração aberta do mundo", é necessariamente um "diálogo entre o ser social e a consciência social" (Thompson, 1981), transformando tanto agentes individuais como coletivos. Ela é, portanto, do âmbito da cultura comum, entendida por Williams como o domínio das experiências compartilhadas que, consciente ou inconscientemente, conecta todos aqueles que vivem em uma mesma sociedade (Williams, 1961; Hoggart 2013). Logo, não se trata de uma perspectiva abstrata e a-histórica, mas da contingência que permite que as pessoas ajam de uma determinada maneira em um tempo e lugar, diferentemente de outras que agiram nos mesmos ou em outros tempos e lugares. Daí ser possível pensar os sentidos e as sensibilidades em termos de estrutura de sentimentos, noção cunhada por Williams para explicar como, a despeito de inevitáveis nuanças, homens e mulheres de uma dada sociedade compartilham necessidades, interesses e expectativas que, se não são coincidentes, orbitam em torno de um mesmo fundo comum, necessariamente dialógico (WILLIAMS, 1961; BRESCIANI, 2004; HOGGART, 2013).

Em uma chave muito próxima, Edward Thompson apropriaria da Economia a noção de economia moral, para explicar os motins contra a fome e a carestia observados no Inglaterra do século XVIII. Para o autor, em claro debate contra os historiadores da economia marxistas ou funcionalistas, muitos dos motins registrados não tinham um caráter "ideológico" ou mesmo econômico como motor primeiro - a fome, por exemplo. Antes, muitas comunidades de trabalhadores se rebelavam, até mesmo de forma violenta, por observarem mudanças nos padrões de atitudes dos proprietários, dos juízes e dos dirigentes 
políticos em relação àquilo que era a tradição. Ou seja, políticas de proteção e acolhimento dos mais pobres, valorização do trabalho contra a especulação, cumprimento das leis baseadas nos costumes etc. Justamente na passagem de uma cultura consuetudinária para outra baseada nas leis do mercado, as quais, aliadas aos eventos naturais aumentavam a carestia dos mais pobres, novas sensibilidades eram definidas na medida em que os padrões de comportamento individual e coletivo sofriam as pressões do capitalismo que se afirmava, alterando drasticamente a vida de uma determinada sociedade.

Inscrita em uma história social da cultura, a educação dos sentidos e das sensibilidades não pode ser descolada dos problemas inerentes a cada sociedade, sejam eles de ordem econômica, política ou social, sobretudo no que se refere à vida dos trabalhadores. Para os dois autores aqui destacados é justamente a noção de cultura que parece sintetizar a inter-relação entre aquelas dimensões da vida material. E se a cultura é do domínio do simbólico, certamente também é do domínio da ação e da experiência humanas, profundamente marcada pelos usos que podem ser feitos dos e com os corpos, seja no exemplo dos motins, das lutas políticas ou das formas educativas, que vão muito além da dimensão retórica. Aliás, mesmo a retórica comporta uma dimensão teatral que é eminentemente corporal.

\section{AS FONTES COMO INDÍCIOS DOS DOMÍNIOS DO CORPO NA HISTÓRIA: IMPRENSA - TEXTOS, ICONOGRAFIA, VOZES.}

Seria um truísmo afirmar que o conhecimento histórico do corpo é sempre indireto e só pode ser mediado pelos registros documentais perpetrados pelas sociedades pretéritas. ${ }^{4}$ Então, de antemão, praticamente qualquer tipo de

\footnotetext{
${ }^{4}$ A noção de evidencia foi problematizada por Ginzburg (1989) no seu genial ensaio Exphrasis $e$ citação. O que buscamos nos estudos que vimos realizando, é tomar a imprensa como manancial de vestígios, rastros, de modo a perseguir as diferentes possibilidades de formação dos trabalhadores (GINZBURG, 1987).
} 
material se presta ao estudo histórico dos sentidos e das sensibilidades. No entanto, tenho privilegiado como suporte documental a imprensa, em um sentido lato, seja na sua dimensão textual ou imagética, como caminho privilegiado para apreender o que chamo de processos de definição e transformação das sensibilidades ao longo do tempo. Do ponto de vista textual, venho considerando uma diversidade de materiais impressos, tais como jornais, revistas, livros, panfletos, relatórios etc., como veículos portadores de vestígios da educação dos sentidos/sensibilidades (TABORDA DE OLIVEIRA, 2017). Por si só eles são possuidores de uma materialidade que pauta usos do corpo textura, cheiro, tamanho, cores, formas de produção e circulação - representam diferentes graus de interação entre os indivíduos - leitura individual, em voz alta, em espaços públicos ou privados, além de expressar distintas formas de pensamento e, muitas vezes, prescreverem comportamentos. A imprensa periódica, em especial, pode ser considerada um verdadeiro mosaico dos dilemas de uma sociedade, permitindo capturar toda a sua diversidade, inclusive no que se refere às tensões entre novos e velhos padrões de atitude e comportamento. Em relação a ela precisamos reconhecer aquela que pode ser considerada "oficial", patrocinada por diferentes instâncias estatais ou governamentais, mas também aquela que assume um caráter geral no que se refere à circulação de ideias, comportamentos, divulgação ou crítica dos costumes, aí incluída a imprensa operária em suas mais diferentes expressões: socialista, anarquista, católica etc. (BARREIRA, 2012 e 2018; BILHÃO, 2008; CRUZ, 2000; SOUSA, 2002; NOGUEIRA, 2012).

Em relação às imagens, podemos pensar tanto naquelas que constam na imprensa - desenhos, gravuras, charges, fotografias etc., em sua relação com o texto ou como forma comunicativa dele independente. Mas podemos considerar, também, a iconografia, que se expressa nas artes plásticas, na escultura, na fotografia, do design, na arquitetura, e que pode ou não ser considerada em uma perspectiva estética, uma vez que primeiramente significa trabalho humano, expressão da mente criativa de homens e mulheres (WILLIAMS, 2003). Nesse caso, trata-se de um tipo de produção que afeta 
diretamente o seu observador, sem a necessidade dos recursos textuais, sendo a sua forma e o seu conteúdo, clara e primeiramente destinados à captura dos sentidos. ${ }^{5}$ Tratar a iconografia implica levar em consideração as mudanças no plano da disponibilidade e da transformação tecnológica (cores, texturas, qualidade dos suportes, história das técnicas - modos de fazer - a sua destinação, circulação e recepção...), assim como a representatividade que certo tipo de produção tem em cada tempo, seja como expressão de valores consagrados ou como questionamento aberto dos mesmos. O que importa no âmbito das minhas preocupações é o quanto o trabalho com a cultura e a sua transformação implicou tensão entre sensibilidades concorrentes, para a qual muitas vezes confluíram diferentes perspectivas educativas para os trabalhadores. Segundo Williams, a expansão das oportunidades educacionais, da qual a cultura de massa é uma expressão, no caso da Inglaterra, ofereceu as condições de transformações radicais no âmbito da sensibilidade da sua população, ainda que Hoggart (2013) questione a qualidade daquilo que por ela foi destinado aos trabalhadores. ${ }^{6}$

Um terceiro plano documental inclui a história oral nas suas mais diversas expressões (histórias de vida, trajetórias profissionais, estudos da memória etc.). Ela nos oferece um conjunto de possibilidades de compreensão das mudanças nos padrões de sensibilidade dos trabalhadores em dado tempo e lugar. Isso porque é uma ferramenta que permite inquirir como os sujeitos dispuseram dos seus corpos ao longo das suas vidas, como interagiram com o mundo, como reagiram aos imperativos sociais e culturais, como captaram e que uso fizeram daquilo que os seus sentidos lhes ofereceram (BATINI, 1991; FOOT HARDMANN, 2002; ROSSI, 2000; TABORDA DE OLIVEIRA, 2014c). A particularidade deste tipo de registro, é que dele é possível extrair um registro

\footnotetext{
5 Uma discussão estimulante das relações entre os historiadores e a iconografia, a partir da crítica a "compartimentação entre as disciplinas" nos foi legada por Ginzburg (2010).

6 Para o autor a cultura de massa não se reveste necessariamente do mesmo caráter mefistotélico que supõe o conceito de indústria cultural, cunhado por Theodor Adorno. Ainda que a cultura de massa possa comportar muitos problemas que devem estimular a crítica, Williams considera que ela expandiu as oportunidades de formação e fruição cultural, sobretudo para os grupos sociais marginalizados.
} 
do passado diretamente a partir dos agentes da ação. Obviamente que também aqui o diálogo com as fontes requer todo tipo de salvaguarda metodológica. No entanto, a história oral e os estudos sobre a memória parecem nos oferecer um tipo de registro que implica apenas a mediação/seleção do sujeito da ação e da fala, sem a interferência direta de outro tipo de suporte mediador que não seja a sua própria memória, que é sempre social, a sua percepção dos fatos, as quais exigem do historiador da educação cuidados específicos. Mas só por isso ela já se converteria em um estimulante manancial para os estudos sobre a história da educação dos sentidos e das sensibilidades dos trabalhadores.

Ainda pouco utilizados nas pesquisas que venho conduzindo até aqui, não devemos negligenciar outros suportes que permitam aferir outras formas de afetação dos sentidos. Por exemplo, podemos pensar naqueles registros que ultrapassam o imperativo do olhar e do tato, privilegiados pela imprensa, pela iconografia ou a história oral. São os registros sonoros, olfativos ou gustativos já estudados por Mintz (2003), Weber (2011), Wisnik (1989), e que requerem outros tipos de procedimentos da parte dos historiadores da educação, os quais os impelem necessariamente a diálogos com outros campos disciplinares.

\section{ALGUMAS POSSIBILIDADES DE ANÁLISE: A IMPRENSA PERIÓDICA.}

O meu objetivo não é esgotar, aqui, as possibilidades de análise dessa vastíssima e variadíssima possibilidade documental. Pretendo oferecer uma pequena mostra de como tenho operado, individualmente ou em parcerias, no que se refere ao enfrentamento da documentação para compreender historicamente a educação dos sentidos e das sensibilidades de diferentes categorias de trabalhadores.

Uma das nossas primeiras iniciativas empírico-analíticas passou pela análise do jornal Minas Gerais, órgão oficial do Governo do Estado, mas que em muito supera o caráter meramente legislativo comum em publicações com 
aquele escopo. Já nas suas primeiras edições nos deparamos com significativas considerações de Alfredo Camarate $^{7}$ sobre o que viria a ser a futura capital mineira para o século XX, em um exercício estimulante de imaginação:

Pelas ruas largas, explendidamente calçadas de paralalepipedos, escrupulosamente varridas, irrigadas a bomba, passadas a escova de noute, começam a transitar os vendilhões de toda a especie e ostentando as suas mercancias, com uma elegância de agrupamentos de cores, com uma esteira de linhar, com tão requintado aceio, que fazem lembrar as manhas hollandezas, na cidade de Amsterdam (...)

(...) É o vendedor de hortaliças, não já o quitandeiro sujo, esfarrapado; mas um modesto filho do povo, que tem agua grátis ou extremamente barata, para que se lave com desafogo e que, pela educação e hábitos da freguezia, teme a concurrencia de outros mais limpos, mais cuidado, nos trajes e na palavra.

O vendedor de hortaliças conduz, não uma carrocinha; mas uma carroça puxada por um burro medio, escovado à brasa, alimentado sem sordidez; (...)

Dentro da carroça, pintada e envernizada à estufa, lavada, com os cuidados de um landau particular, accumulam- se verdes e tenras couves, com viços de quem nasceu em terrenos devidamente adubados; repolhos de muitos kilos de peso intervallados por esses globosinhos apetitosos, rouxos, luzidios, que nascem das sementes famigeradas de Bruxellas; alfaces completamente brancos no talo e nas nervuras e esbatendo-se num verde gaio, que promette estalinhos frescos e condescendentes, que se comem, apresentando resistencias de mulher faceira, esquivamentos fugazes, de quem morre por ser vencido e triumphado. Destacando-se, pela intensidade dos fulgores da purpura molhos de rabanetes completamente livres da terra em que nasceram, por continuadas ( ilegível ); os ponteagudos e alvos nabos, a chicória farpada e auvi-verde, os brilhantes pomos de ouro, como lhes chamam os italianos, disputando em tamanho, colorido e pezo uns com os outros; o agrião saudavel, os condimentos cheiros; uma orgia de verduras, enfim, que atestam, a um tempo, a prodigalidade do solo e a profisciencia do horticultor. (MINAS GERAES, 21 Janeiro 1894 )

\footnotetext{
${ }^{7}$ Alfredo Camarate, português, formado arquiteto na Inglaterra, foi provavelmente o primeiro cronista de Belo Horizonte. Sob o pseudônimo Alfredo Riancho assinou uma coluna no jornal Minas Gerais, entre março e dezembro de 1894, intitulada "Entre Montes e Vales", além de outros textos esparsos pelo jornal, sobretudo na sessão Collaborações. Mais informações sobre o autor, a sua trajetória e a sua formação estão disponíveis no estimulante trabalho de Segantini (2010).
} 
O primor da imagem projetada pelo autor da crônica parece fazer saltar aos nossos olhos o choque entre dois tipos de sensibilidades. A nova cidade, em construção, atraía por todo lado o conjunto de realizações que uma urbe moderna poderia oferecer, como bem assinala Segantini (2010). Arruamento ordenado, higiene, beleza, até mesmo o equipamento do vendedor de hortaliças merecia o seu comentário. Afinal, em um novo mundo urbano até mesmo os trabalhadores deveriam ser "reformados". A educação e os hábitos aparentemente refinados dos seus habitantes são destacados no registro como um traço constitutivo do novo espaço. As referências aos produtos ali vendidos remetem ao seu brilho, à sua maciez, à sua textura, ao seu aspecto saudável que inebriava os sentidos: cheiros, cores, texturas, "estalinhos frescos" compõem um tipo de percepção do ambiente circundante, projetado pelo autor, em relação ao que seriam as velhas formas de viver que marcariam a antiga capital do Estado e os antigos modos de vida do país. No elogio projetado em uma cena cotidiana, com a devida dose de idealização oferecida por Camarate, na qual os sentidos são arrebatados pelo frescor dos novos tempos, uma nova sensibilidade se anunciava sem que precisasse ser prescrita. Bastava ao observador atento fruir aquele conjunto de experiências para que compreendesse que o mundo que se avizinhava, marcado pela modernização da urbe, só poderia ser um mundo almejado, desejado, no qual mesmo os mais humildes trabalhadores seriam valorizados. Em uma operação esteticamente certeira, Camarate atrelava a reforma do homem à reforma da cidade, pois nela os antigos costumes, representados pela sujeira, pelo descuido, pela desordem e pelos hábitos rudes, seriam "positivamente" substituídos pelas novas formas de viver na cidade que se materializava no que era pouco mais que um caminho no sertão mineiro.

Procurando traçar paralelos com os "centros culturais mais avançados do mundo", os lugares mais "educados" em outros continentes, o mesmo jornal noticiava a realização do um evento musical, ainda em Ouro Preto, a antiga capital. 
O theatro, em que se ia dar a Favorita, não era um edificio que pretendesse ( ilegível ) parelhas com o Grand Opera de Pariz, nem mesmo com qualquer destes theatros, ( ilegível ) pelo agigantado das dimensões e pelos ( ilegível ) primores da ornamentação. (...)

(...) Quando me sentei na cadeira, já estava grande numero de homens e senhoras na plateia e os camarotes começavam a povoar-se de famílias, cujos vestuários não descrevo, pelo muito que sempre fui avesso no capitulo de modas; mas que, em todo o caso, me impressionaram, pela despretenção do corte e pela suavidade da combinação das côres.

(...) Notei apenas que o publico aplaudiu, no fim dos trechos capitaes e sobretudo quando terminava cada acto.

(...) Essas explosões de enthusiasmo mal cabidas e que perturbam a atenção dos verdadeiros amantes de musica não appareceram sequer uma vez. (MINAS GERAES, 1 fevereiro 1894).

O observador, não identificado na matéria, perscrutava atentamente as atitudes de outros ouvintes, capturando suas expressões e tecendo sobre eles os mais diversos tipos de comentários. O espaço não era comparável àquilo que se supõe que tenha visto em outros lugares, sendo tão despretensioso quanto a vestimenta dos frequentadores. Nem por isso o observador deixou de enaltecer o entusiasmo comedido daquele público que parecia se comportar de acordo com os protocolos definidos para frequentadores daquele espetáculo. $\mathrm{O}$ autor nos produz a impressão de que havia modos "certos" de agir em relação aos espetáculos artísticos ao elogiar a conduta do público em relação a audição. Afinal, ele só aplaudia nos "trechos capitais" e ao final de cada ato, sem perturbar os "verdadeiros amantes da música”. Não podemos falar, sem que pareça haver uma pretensão educativa, em algum tipo de indício de educação do(s) sentido(s), um elogio à forma adequada de fruir a música e comportar-se em público? ${ }^{8}$

Pouco mais de 20 anos depois, as páginas do mesmo periódico

\footnotetext{
8 Tanto o trabalho de Weber (2011), quanto o de Sennett (2014) ajudam a compreender a mudança de atitude das plateias em relação às apresentações musicais ou teatrais entre os finais do século XVIII e a primeira metade do século XIX. Aquele novo padrão, observado em Ouro Preto, sugere a atualidade dos comportamentos considerados polidos, educados, manifestados pelo público daquela cidade em relação a alguns dos principais centros urbanos do mundo.
} 
apresentavam um conjunto de textos publicados pelo padre integrista clareteano, Francisco Ozamis, entre 1913 e 1916, em uma coluna denominada Orientações Pedagógicas. Aquelas intervenções no espaço público tinham o claro fito prescritivo, a partir das críticas que o religioso fazia à modernização que abalava os costumes e a estrutura da família e da sociedade. Claramente antimoderno, ele escrevia sobre a educação física, intelectual e moral, na esperança de reverter o que considerava a "decadência da civilização cristã". 9 Uma das suas obsessões era com a sexualidade dos jovens:

A vida sedentária e falta de exercicio produzem a lentidão na circulação do sangue e desarranjo dos centros nervosos, sendo esta perturbação nervosa causa da irritabilidade sexual.[...] como indica o ilustre Dr. Grasset na obra Idées Paramedicales, pag.18 - estes exercícios para attingirem o almejado fim hão de ser "regulares", moderados e progressivement prolongées (sic). (MINAS GERAES, 19/10/1913, p. 7).

Bastante conectado com as ideias "científicas" do momento, Ozamis reivindicava a exercitação física, coqueluche da época, como lenitivo para a excitação sexual, uma vez que a sua pauta educativa era assumidamente moralizadora dos costumes:

A moral individual afirma os deveres em relação a nossa pessoa. [...] É o corpo um instrumento de conhecimento do serviço da intelligencia e um instrumento de acção sob as ordens da vontade. (OZAMIS, 1915, p. 255)

A saude do corpo torna possíveis os enthusiamos da sciencia, facilitando juntamente a pratica da virtude. A conservação da saúde é o primeiro dever da moral individual, porque é o fundamento dos outros deveres superiores. (OZAMIS, 1915, p. 257)

Em tom trágico e grandiloquente, o padre reivindicava: "Dentro destas

${ }^{9}$ Dados biográficos sobre Francisco Ozamis podem ser encontrados em Gonçalves (2009). Sobre a sua produção em relação à educação, ver Vago e Oliveira (2009) e, especialmente, Vieira (2013). 
orientações e tratando-se da educação physica, queremos apontar algumas idéias sobre a educação da moralidade e melhora da castidade, matéria alias que é mola real dessa educação, visto que a castidade é a força da mocidade, e o vicio contrário é o terrível micróbio que suga as energias do seu organismo”. (MINAS GERAES, 15/11/1913, p. 3)

Enaltecendo o exercício da vontade e o sacrifício para aquisição de novos hábitos sãos e morais, o autor, que criticava outras formas de educação do corpo, contrapunha-se a todo e qualquer tipo de prazer que elas pudessem suscitar. Para ele, existiriam

(...) duas philosophias que compartilham o império moral do mundo: a philosophia do sacrifício e a philosophia do prazer. Das orientações respectivas dessas duas idéas antitheticas surgiram as escolas e os systemas divergentes que na arena social combatem pela conquista do direito, da justiça e do mal ou da força brutal com sua lúgubre comitiva de martyrios sanguinolentos. [...] Só a philosophia do sacrificio, em certo modo, é que pode levar a paz ao seio da família humana. É claro, porém, que não há formação moral sem virtude, isto é, hábitos adquiridos de resistência ao mal e pratica do bem. Ora... não é possível que a justiça, como a ordem moral, triumphe do mal sem sacrifício. [...] Começa a sentir-se necessidade do sacrifício já na educação physica.(MINAS GERAES, 19/10/1913, p. 7)

Citando a psicologia sexual, rematava:

Quem aprofundar no estudo da psychologia sexual há de achar que a única defeza verdadeiramente efficaz consiste em impedir que tome conta a tentação do mundo das imagens. Essa observação baseia-se numa lei fundamental da Psychologia, isto é, toda a imagem está ordenada a uma idéia e esta tende ao acto (...)

Importa sobre tudo dirigir a sensibilidade e ordenar a paixão, principalmente a do amor. Não são detestáveis as paixões quando os objectos em que se concretizam não o sejam. É doutrina estóica a condemnação das paixões e a necessidade da sua morte para a pratica da virtude. [...] Ordenae a paixão e dirigi a sensibilidade. Idealizae, melhor, tanto o sentimento como a paixão. (OZAMIS, 1915, p. 67-68) 
Para o padre, sentidos, paixões, sensibilidade deveriam ser submetidos ao escrutínio da razão. Mas razão, para a tradição integrista a qual ele estava vinculado, significa o atrelamento aos princípios religiosos ultraconservadores.

É necessário que o mundo das imagens, sentimentos e paixões se submeta ao critério da razão esclarecida. As paixões são forças que a vontade utiliza quando lhe são subordinadas. A soberania da vontade tem essas inimigas, quando não foram vencidas, pois escravas se transformam em dominadoras. É um dos pontos principaes do trabalho educativo dar á vontade reservas de virtude e energia para os momentos em que o dever se apresenta difficil. É bitola dos grandes caracteres e resistência ao mal e a Victoria da liberdade sobre o mau instincto. A sensibilidade é outro inimigo da vontade livre. $\mathrm{O}$ homem há de vigiar o desdobramento do sentimento. Porque quase todos os moveis dos nossos actos encontram secretos impulsos na sensibilidade. Os gozos puros da virtude, escreveu um illustre philosopho, são o premio do triumpho da razão sobre a sensibilidade. É mister envidar todos os esforços para reforçar a sensibilidade physica, porque os excessos das sensibilidades nos levam ao suicídio pelo aborrecimento, ou a uma morte prematura. Entre os meios práticos podem indicar-se o conhecimento próprio, o trabalho e a direcção de um educador. [...] Um meio geral que muitos philosophos pagãos recommendaram é o exame de consciencia ou reflexão regressiva sobre o dia. $\mathrm{O}$ exame de consciência nos dá conhecimento da nossa psychologia particular, acautela-nos para o futuro e nos augmenta o brio para novas luctas. (OZAMIS, 1915, p. 256-258)

A cruzada moralizadora ensejada pelo padre espanhol não só dava eco para as doutrinas católicas ultramontanas, como se valia de uma interlocução clara e contundente com a reforma dos costumes que se assistia nas décadas iniciais do século XX. Não parece exagero supor que a presença dos esportes como prática que lentamente se afirmava, o elogio do corpo como vetor de educação, teorias médicas e psicológicas que se ocupavam da sexualidade, o "materialismo da vida moderna", tudo se combinasse na verve militante do religioso pela reforma moral da sociedade, uma vez que representavam "perigo" para a formação dos jovens. Ora, a sua tônica faz supor que, se era necessária uma cruzada pela imprensa contra a degradação dos costumes, então é porque se podia observar naquele período um conjunto de comportamentos sociais, ou 
mesmo de ideias, que se contrapunham à força da tradição, da qual a Igreja Católica se considerava a maior guardiã. Não estaríamos diante de um choque entre sensibilidades distintas? E não era justamente pelo corpo e a sua educação que elas se manifestariam?

\section{A IMPRENSA OPERÁRIA E A FORMAÇÃO DAS FAMÍLIAS TRABALHADORAS.}

Em diferentes momentos da trajetória da pesquisa que venho percorrendo nos últimos anos, dediquei-me a perscrutar a presença de sinais que pudessem revelar preocupações com a educação dos sentidos e das sensibilidades na vida dos trabalhadores (DRUMMOND E TABORDA DE OLIVEIRA, 2015; TABORDA DE OLIVEIRA, 2019b), dimensão a ser privilegiada nessa nova fase das nossas investigações. Se por um lado muitos dos periódicos se ocuparam de questões político-ideológicas, atuando como propagandistas de partidos, sindicatos ou assemelhados, nem por isso deixaram de dar visibilidade à organização da vida ordinária da gente comum. A militância, fosse socialista, anarquista, liberal ou católica, não era um empecilho para que brotasse das páginas de inúmeros periódicos a preocupação com a elevação intelectual e moral do povo, denotando a necessidade de desenvolvimento de novas sensibilidades em relação ao mundo do trabalho e às condições de vida das famílias de trabalhadores, como bem tem mostrado autores como Bilhão (2008), Nogueira (2012), Souza (2002) e Taborda de Oliveira (2019b).

Um exemplo nos é oferecido pelo revista Educação Social, publicada em Portugal, e sistematicamente estudada por Luiz Carlos Barreira (2012 e 2018). De um estimulante conjunto de artigos dedicados a propagar o direito à educação de todas as classes sociais, destaco alguns que parecem desvelar justamente o choque entre diferentes sensibilidades.

Tratando dos efeitos do cinematógrafo, novidade educativa na década 
de 1920, Deolinda Lopes Vieira denunciava o "coeficiente sugestionador" do cinema e dos filmes policiais:

(...)impressionando e empolgando, quase sempre de uma maneira dissolvente, as imaginações fogosas e mal-educadas, convertem o cinematógrafo numa verdadeira escola do crime.

Além disso, por ser um espetáculo barato, mais acessível, por consequência à bolsa do povo e da criança, e despertando e aguçando, habilmente, a curiosidade do público, com seus cartazes vistosos reproduzindo lances emocionantes, com suas luzes deslumbrantes e com suas campainhas retinindo, impertinente, atraem, como nenhum outro, o público menos educado e, por isso mesmo, mais sugestionável (VIEIRA, 3, 1926, p. 44, grifos meus).

A autora, escrevendo em uma revista de inspiração anarquista, parece estupefata com os avanços da possibilidade de afetação da vida dos mais pobres pela tecnologia que permitiu o cinema afirmar-se como produtor de valores. Denotando um certo assombro com a sua potência, denunciava os efeitos deletérios que a sua prática poderia produzir. Mas as suas considerações claramente remetiam a todo um universo de sensações que aquela prática potencialmente produziria. E não apenas os filmes eram potenciais formadores dos seus espectadores, mas os cartazes que os divulgavam inebriariam os sentidos de maneira a emocionar o público e afetar a sua educação. Sintomaticamente a autora se referia a uma possível "escola do crime", denotando um entendimento não necessariamente positivo do que poderia ser a arte de educar. Para ela as crianças tenderiam a reproduzir nos mais diversos ambientes, a começar pelo espaço de recreio escolar, práticas que revelariam "baixeza moral". A solução seria proibir às crianças com sete anos ou menos, o acesso aos filmes, usando o cinematógrafo para projeções condizentes com o seu desenvolvimento, pois aqueles eram "fatigantes para a vista e para o cérebro" (p. 45). Ou seja, a autora se preocupava tanto da educação pelos sentidos, com forte acento moralizador, quanto com a educação dos sentidos, pelo que os filmes tinham de potência para afetar o aparato sensorial dos pequenos. Em ambos os 
casos, a sensibilidade daí decorrente seria aquela que preservasse as crianças dos efeitos pretensamente danosos que os "films policiais e sangrentos" poderiam produzir sobre elas.

Tratando-se uma novidade no mercado dos bens culturais, portanto, no mercado pedagógico, o cinema e os filmes abalavam a estabilidade de um tipo de sensibilidade que ainda não se adequara aos ritmos do mundo industrial, como bem acentuou Benjamin (2009). Deolinda Vieira parecia ela mesma chocada com a novidade que ameaçava as "boas práticas educativas". Denominava assombrosos aqueles filmes que impressionavam e empolgavam, eram emocionantes e deslumbrantes. O seu caráter sedutor era combatido pela autora do artigo como algo deletério, por isso precisava ser combatido. Não estamos diante de uma clara expressão de choque entre o que é bom ou ruim, melhor ou pior, certo ou errado, em um momento de amplos debates no que se refere à reforma da escola e à reforma social, com franca preocupação em relação à educação dos filhos dos trabalhadores?

Ainda na revista Educação Social, César Pôrto tecia considerações sobre a educação estética em uma perspectiva anarquista. Fazendo o elogio da literatura afirmava que ela

(...) educa o ouvido, um pouco a vista, a imaginação, o entendimento concreto, e a razão [...]. Alarga o interesse e a simpatia; por isso o âmbito moral [...]. Desenvolve a linguagem, o dom que por excelência nos faz homens. Aperfeiçoa esse mágico instrumento, sem o qual nunca poderíamos transferir de geração para geração e comunicar de uns para os outros as nossas experiências e princípios. É forma e fundo. É emoção, visionamento, ouvido e pensamento (PÔRTO, 1, p. $88,1924)$.

A educação pela via das obras literárias, para o autor, não só educaria sentidos e sensibilidades, como permitiria que todos compartilhassem, intercambiassem experiências, dando unidade à aventura humana. Aprender a ouvir, a observar, a fruir e a compartilhar. Novamente, se a literatura é o suporte 
pelo qual se poderia educar pelos sentidos, a assertiva que ela educaria o ouvido ou falaria pelos olhos, ambas expressões de César Pôrto, sugere que haveria formas diversas de ver, ouvir, logo, sentir, conforme fosse potencializada a capacidade humana de partilhar a vida, o que distanciava a perspectiva daquele autor da voga pedagógica centrada no individualismo. ${ }^{\mathbf{1 0}}$

$\mathrm{Na}$ análise desses diferentes suportes documentais, podemos capturar uma perspectiva formativa que expressa um conjunto de preocupações sobre o compartilhamento da vida, a interação entre os indivíduos, a sua capacidade de produzir um mundo comum, além de ajudar a compreender o sentido de cultura comum proposto por Williams como uma chave para entender a história dos trabalhadores. Que é, também, a história do seu processo de formação, como bem sinaliza Alessandra Shueller (2014) ao sugerir uma história da educação que transborde os limites da escola.

(...) Não estamos nem de longe propondo o abandono dos estudos sobre a escola como instituição de educação, em seus moldes mais clássicos. Entretanto, é necessário avançar na proposição de novos olhares sobre o mesmo problema de pesquisa, bem como novos objetos e novas abordagens. Podemos pesquisar outras formas e práticas de ensino - aprendizagem vivenciadas fora das salas de aula, nos espaços sociais plurais, mas que também estão repletas de tensões políticas e sociais. Por exemplo, pensamos aqui no tirocínio artesanal das oficinas; no âmbito do trabalho urbano e rural; mas heterogêneas formas de relações familiares; nas práticas difusas e informais de transmissão de valores; nos meios de comunicação de massa; no teatro, nas redes e tecnologias de informação, etc., etc. (SCHUELER, 2014, p. 21).

Os exemplos aqui arrolados são apenas pequenas mostras que visam ilustrar a potencialidade da imprensa e da iconografia como possibilidade de compreensão dos processos de formação. Muitos outros arquivos esperam para serem vasculhados, muitos documentos podem ser mobilizados de modo que possamos incrementar esse âmbito de estudos ainda pouco desenvolvido entre

${ }^{10}$ Sobre as possibilidades das fontes imagéticas para o estudo dos sentidos e das sensibilidades ver Taborda de Oliveira (2014b) 
nós. Nesse sentido, pela análise da imprensa e da iconografia são inúmeras as entradas de pesquisa possíveis para além daquelas aqui exemplificadas. Entendo que podemos arrojar luzes sobre a história das mulheres trabalhadoras, do associativismo como possibilidade de formação, das tensões entre formação e educação profissional, do lugar da infância no mundo do trabalho, das relações entre vadiagem e trabalho, entre tantos outros, temas que vem estimulando os estudos do grupo por mim coordenado nos últimos anos, e que pretendemos amplificar nos anos vindouros.

\section{REFERÊNCIAS}

ANSART, Pierre. A gestão das paixões políticas. Curitiba: Editora da UFPR, 2019.

BAKHTIN, Mikhail. Estética da criação verbal. São Paulo: Martins Fontes, 2011 [1979].

A cultura popular na Idade Média e no Renascimento. São

Paulo: Hucitec: Brasília: Editora da Universidade de Brasília, 1999 [1977].

BARREIRA, Luiz Carlos. Educação libertária: a experiência da Escola Oficina No. 1 de Lisboa (1908/1909-1918). In: CARVALHO, Marta; PINTASSILGO, Joaquim (orgs.). Modelos culturais, saberes pedagógicos, instituições educacionais. São Paulo: EDUSP/FAPESP, 2011.

. Educar ou instruir? Narrativas anarcossindicalistas nos primeiros anos da República Portuguesa: Revista Lumen (Lisboa, 1911-1913). Cadernos de História da Educação, v.17, n.1, p.213-231, jan.-abr. 2018

BATINI, Tito. Memórias de um socialista congênito. Campinas: Editora da UNICAMP, 1991.

BENJAMIN, Walter. Estética y política. Buenos Aires: La Cuarenta, 2009.

Rua de mão única/Infância berlinense: 1900. Tradução: João Barrento. Belo Horizonte; Autêntica, 2013.

BILHÃO, Isabel. Identidade e trabalho: uma história do operariado portoalegrense (1898-1920). Pelotas: EUELE, 2008. 
BRAGHINI, Katya, MUNAKATA, Kazumi e TABORDA DE OLIVEIRA, Marcus Aurelio (orgs.). Diálogos sobre a educação dos sentidos e das sensibilidades. Curitiba: Editora da UFPR, 2017.

BREPOHL, Marion et alii (Orgs.). Sentimentos na História: linguagens, práticas, emoções. Curitiba: Editora UFPR, 2012.

BRESCIANI, Stella e NAXARA, Márcia. Memória e (res)sentimento: indagações sobre uma questão sensível. Campinas: Editora da Unicamp, 2004.

COCCIA, Emanuele. A vida sensível. Florianópolis: Cultura e Barbárie, 2010.

CORBIN, Alain. História dos tempos livres. Lisboa: Teorema, 2001.

CRUZ, Heloisa. São Paulo em papel e tinta: periodismo e vida urbana 1890/1915. São Paulo: EDUC, 2000.

DEMARTINI, Anne-Emmanuelle. Sensibilité(s) In: GAUVARD, Claude e SIRINELLI, Jean-François (dir). Dictionnaire de l'historien. Paris: Presses Universitaires de France, 2015.

DRUMMOND, Caroline e TABORDA DE OLIVEIRA, Marcus Aurelio. A formação do trabalhador no jornal O Operário, de Montes Claros (1932-1945): a produção de novas sensibilidades "sem classes". In: MESQUITA, Ilka Miglio et alii (orgs.) Moderno, modernidade e modernização: a educação nos projetos de Brasil - séc. XIX e XX. Belo Horizonte: Mazza, 2015.

DUSSEL, Inés y GUTIERREZ, Daniela. Educar la mirada. Buenos Aires : Manantial : FLACSO, 2006.

ESPÓSITO, Roberto. As pessoas e as coisas. São Paulo: Rafael Copetti Editor, 2016.

FOOT HARDMAN, Francisco. Nem pátria, nem patrão! $3^{\mathrm{a}}$. edição. São Paulo: Editora UNESP, 2002.

GAY, Peter. A educação dos sentidos. São Paulo: Companhia das Letras, 1999.

GINZBURG, Carlo. O queijo e os vermes. São Paulo: Companhia das Letras, 1987 [1976].

. Exphrasis e citação. In: A micro-história e outros ensaios. Lisboa: Difel, 1989.

Investigando Piero. São Paulo: Cosac Naify, 2010 [1994]. 
GONÇALVES, Marcos.As tentações integristas: um estudo sobre as relações entre catolicismo e política no Brasil (1908- 1937). Tese (Doutorado em História) - Faculdade de Filosofia Ciências e Letras, Universidade Federal do Paraná, Curitiba, 2009.

HOGGART, Richard. La cultura obrera en la sociedade de masas. Buenos Aires: Siglo Veintiuno Editores, 2013 [1957].

MINTZ, Sidney. Sabor a comida, sabor a libertad. México: Ediciones de la Reina Roja, 2003.

MOTHÉ, Daniel. L'utopia del tempo libero. Torino: Bollati Boringhieri Editore, 1998 (1997].

NOGUEIRA, Vera Lúcia. A escola primária noturna em Minas Gerias (1891-1924). Belo Horizonte: Mazza Edições, 2012.

PINEAU, Pablo. Estética e historiografia de la educación: la construcción de um dispositivo temprano de intervención duradera. In: TABORDA DE OLIVEIRA, Marcus Aurelio (org.) Sentidos e sensibilidades: sua educação na história. Curitiba: Editora UFPR, 2012.

PINEAU, Pablo e DI PIETRO, Suzana. Aseo y pesentación: un ensayo sobre la estética escolar. Buenos Aires: el autor, 2008.

PORTO, Cezar. O teatro e a educação. Educação Social. Lisboa, n. 1, p. 88, 1924 .

ROSSI, Giovanni. Colônia Cecília e outras utopias. Curitiba: Imprensa Oficial, 2000.

SCHUELER, Alessandra Frota Martinez. Educação, experiência e emancipação: contribuições de E. P. Thompson para a história da educação. Trabalho necessário, Rio de Janeiro, ano 12, n. 18, 2014, p. 1-25.

SEGANTINI, Verona. Fundando sensibilidades, educando os sentidos: dos sujeitos na cidade (Belo Horizonte, uma capital do ano de 1900). Dissertação (Mestrado em Educação). Programa de Pós-Graduação em Educação: Conhecimento e Inclusão Social. Universidade Federal de Minas Gerais. Belo Horizonte, 2010.

SENNETT, Richard. O declínio do homem público: as tiranias da intimidade. Rio de Janeiro: Record, 2014.

SOUZA, Jessie Jane Vieira de. Círculos operários: a Igreja Católica e o mundo do trabalho no Brasil. Rio de Janeiro: Editora UFRJ, 2002. 
TABORDA DE OLIVEIRA, Marcus Aurelio (org.). Educação do corpo na escola brasileira. Campinas: Autores Associados, 2006

. Atividade e natureza: a educação física para o ensino primário. In:

BASTOS, Maria Helena Camara; CAVALCANTE, Maria Juraci (orgs.) O curso de Lourenço Filho na Escola Normal do Ceará. Campinas: Alínea, 2009.

Sentidos e sensibilidades: sua educação na história. Curitiba: Editora UFPR, 2012.

Educação dos sentidos. In: GONZÁLEZ, Fernando Jaime e FENSTERSEIFER, Paulo Evaldo (orgs.). Dicionário crítico de Educação Física. $3^{\text {a }}$. edição. Ijuí: UNIJUÍ, 2014a.

"Eu desisto?" Paredes vivas na cidade: conflitos sociais em cartazes produzidos ao longo da década de 1980, no Brasil. Educar em Revista, n. 51, pp.175-190, mar. 2014b.

La experiencia de una profesora escolar como posibilidad de pensar y hacer de la escuela un lugar de cultura. trayectoria formativa y buenas prácticas educativas. Educacion Fisica y Deporte, v. 33, pp. 125-161, 2014 c.

. Referenciais teórico-metodológicos na pesquisa em História da Educação: para uma história das relações entre sensibilidades, tempo livre e formação. In: BRAGHINI, Katya, MUNAKATA, Kazumi e

TABORDA DE OLIVEIRA, Marcus Aurelio (Org.). Diálogos sobre a educação dos sentidos e das sensibilidades. Curitiba: Editora da UFPR, 2017.

TABORDA DE OLIVEIRA, Marcus Aurelio. Educação dos sentidos e das sensibilidades: entre a moda acadêmica e a possibilidade de renovação do âmbito das pesquisas em história da educação. História da Educação. v. 22, n. 55, pp. 116-132, maio/ago., 2018.

TABORDA DE OLIVEIRA, Marcus Aurelio. O ethos do trabalho nas páginas de periódicos educacionais brasileiros: Trabalhos Manuais como signo da modernização pedagógica (1906 - 1934). Cadernos de História da Educação, v.18, n.2, p.386-405, mai./ago. 2019 a.

TABORDA DE OLIVEIRA, Marcus Aurelio. A educação estética dos trabalhadores nas páginas do jornal Il Grido del Popolo (Piemonte, Itália, 18921905). Educ. rev., vol.35, no.73, p.67-85, fev. 2019b.

TABORDA DE OLIVEIRA, Marcus Aurelio e BELTRÁN, Cláudia Ximena 
Herrera. Uma educação para a sensibilidade: circulação de novos saberes sobre a educação do corpo no começo do século XX na Ibero-América. Revista Brasileira de História da Educação, Campinas-SP, v. 13, n. 2 (32), p. 15-43, maio/ago. 2013.

TABORDA DE OLIVEIRA, Marcus Aurelio e OSCAR, Luisa Belotti. Referenciais teórico-metodológicos nas pesquisas em história da educação: para uma história das relações entre sensibilidades, tempo livre e formação. Revista Esboços, Florianópolis, v. 21, n. 31, p. 171-193, ago. 2014.

THOMPSON, E.P. William Morris: de romántico a revolucionário.Valencia: Alfons el Magnànin, 1988.

THOMPSON, E.P. A miséria da teoria. Rio de Janeiro: Zahar, 1981.

THOMPSON, E.P. Tradición, revuelta y consciencia de clase. $2^{\mathrm{a}} \mathrm{ed}$. Barcelona: Crítica 1984c.

THOMPSON, E.P. A formação da classe operária inglesa. Rio de Janeiro: Paz e Terra, 1987a. 3 volumes.

THOMPSON, E.P. Senhores e caçadores. Rio de Janeiro: Paz e Terra, 1987b.

THOMPSON, E.P. Costumes em comum. São Paulo: Companhia das Letras, 1998.

THOMPSON, E.P. Folclore, antropologia e história social. In: As peculiaridades dos ingleses e outros textos. organização A.L.Negro e S.Silva. Campinas: Ed.Unicamp, 2001c.

THOMPSON, E.P. Os românticos: A Inglaterra na era revolucionária. Rio de Janeiro: Civilização Brasileira, 2002.

TORO, Pablo Blanco. Algunas ideas exploratorias para una historia del control emocional juvenil en la educación secundaria chilena, c.1880-c.1950. In:

Elizabeth Figueiredo de Sá, Regina Helena Silva Simoes y Wenceslau Goncalves Neto (orgs.). Circuitos e fronteiras da história da educação. EDUFES, Vitoria, 2015.

VAGO, Tarcísio Mauro; OLIVEIRA, Cristiana Chaves. Francisco Ozamis: um padre escreve sobre a educação moral, intellectual e physica em Minas Gerais (1902-1929). In: (Re)Visitando as Minas e Desvelando os Gerais.

CONGRESSO DE PESQUISA E ENSINO DE HISTÓRIA DA EDUCAÇÃO EM MINAS GERAIS, Montes Claros., p.109-111, maio 2009.

VEIGA, Cynthia Greive; TABORDA DE OLIVEIRA, Marcus Aurelio (orgs.). 
Historiografia da educação: abordagens teóricas e metodológicas. Belo Horizonte: Fino Traço, 2019.

VIEIRA, Deolinda Lopes. O cinema. Educação Social. Lisboa, n. 3, p. 44, 1926.

VIEIRA, Yuri Vitor Guimarães. Retóricas sobre educação physica, sport e exercício físico no jornal Minas Geraes entre 1913 e 1916. Dissertação (Mestrado em Estudos do Lazer). Programa de Pós-Graduação Interdisciplinar em Estudos do Lazer. Universidade Federal de Minas Gerais. Belo Horizonte, 2013 .

WEBER, William. La gran transformación en el gusto musical. México: Fonde de Cultura Económica, 2011.

WILLIAMS, Raymond. Cultura y sociedad. Buenos Aires: Nueva Visión, 2001.

WILLIAMS, Raymond. Marxismo e literatura. Rio de Janeiro: Zahar, 1979.

WILLIAMS, Raymond. Cultura. Rio de Janeiro: Zahar, 1991.

WILLIAMS, Raymond. La política del modernismo - contra los nuevos conformistas. Buenos Aires: Editiones Manancial, 1997.

WILLIAMS, Raymond. La larga revolucion. Buenos Aires: Nueva Vision, 2003.

WILLIAMS, Raymond. Palavras-chave - um vocabulário de cultura e sociedade. São Paulo: Boitempo Editorial, 2007.

WILLIAMS, Raymond. A política do modernismo. São Paulo: Editora UNESP, 2010.

WILLIAMS, Raymond. Cultura e materialismo. São Paulo: Editora UNESP, 2011.

WISNIK, José Miguel. O som e o sentido: uma outra história das músicas. São Paulo: Companhia das Letras, 1989. 
MARCUS TABORDA DE OLIVEIRA é professor da Faculdade de Educação da Universidade Federal de Minas Gerais. Doutor em História e Filosofia da Educação pela PUCSP (2001).Bolsista em produtividade (1C) do CNPq.

E-mail: marcustaborda@uol.com.br

(1) http://orcid.org/0000-0002-6079-9710

Recebido em: 17 de outubro de 2019

Aprovado em: 08 de dezembro de 2019

(c) (i)

Revista História da Educação - RHE

Associação Sul-Rio-Grandense de Pesquisadores em História da Educação - Asphe

Artigo de acesso aberto distribuído nos termos de licença Creative Commons. 